\title{
Prevalence of Cardiac Risk Factors among People Attending an Exhibition
}

\author{
Mrs. Hepsi Rachel Charles, \\ M.Sc (N)., [Ph.d Scholar], Saveetha University, Chennai. \\ Associate Professor, Medical \& Surgical Nursing, Sri Gokulam College of Nursing, Salem.
}

\begin{abstract}
A study was done to assess the cardiac risk factors among people attending cardiac exhibition at selected hospital, Salem. Quantitative descriptive research design was used for this study. 169 people were selected by using non probability convenience sampling technique. After conducting cardiac exhibition health related data was collected from the participants along with the physiological parameters such as blood pressure, BMI, Waist-Hip ratio. It showed that 121 (71.59\%) were at mild risk, 39(23.07\%) at moderate risk and $9(5.32 \%)$ at severe risk for developing cardiac diseases. The chi square test was used to find out the association between cardiac risk factors among people who attended cardiac exhibition with their demographic and health related variables. The results showed that demographic variables like age, educational status, nature of job and monthly income and health related variables like blood pressure and family history of heart diseases and BMI had significant association with cardiac risk factors. Hence research hypothesis $H_{1}$ was retained at $p<0.05$ level.
\end{abstract}

Keywords: CAD risk factors, Cardiac Exhibition, Demographic variables, Health related variables, Prevalence.

\section{Introduction}

Cardiovascular disease (CVD), (Coronary artery heart disease (CAHD) and stroke), is the leading killer in western societies and its prevalence is also increasing dramatically in developing nation ${ }^{[1,2]}$.According to WHO Global atlas on CVDs prevention and control 2011,cardiovascular diseases remain the biggest cause of deaths worldwide. More than 17million people died from CVDs in 2008, out of which 7.3 million deaths were due to heart attacks. More than 3 million of these deaths occurred before the age of 60 and could have been prevented. The percentage of premature deaths from CVDs ranges from $4 \%$ in high-income countries to $42 \%$ in low income countries, leading to growing inequalities in the occurrence and outcomes of CVDs between countries and populations ${ }^{[3]}$. Preliminary mortality data show that CVD as the underlying cause of death accounted for $37.3 \%$ of all $2,440,000$ deaths in the year 2003 or 1 of every 2.7 deaths in the US ${ }^{[4]}$. In 2008 , CVDs are responsible for 151,377 million DALYs, of which 62,587 million are due to coronary heart disease and 46,591 million to cerebrovascular disease ${ }^{[5]}$.

The prevalence of CAD in India has more than doubled in the past two decades. India topped the world with 1,531,534 CVD related deaths in 2002 and occupied first place in cause of death in current moment based on WHO report, 2009. The median age of first attack in Indians is 53 years. ${ }^{[6]}$

A number of cardiovascular risk estimation systems have been proposed to date, the most well-known being those based on the Framingham risk score ${ }^{[7]}$, Independent systems include Prospective Cardiovascular Munster (PROCAM) ${ }^{[8]}$ study, the Dundee risk disk ${ }^{[9]}$, and $\mathrm{SCORE}^{[10]}$ is the European Cardiovascular Risk Estimation Tool.

\subsection{Need for the Study}

Since CVD (atherosclerosis) is the product of multiple risk factors, it's clear that a comprehensive risk factor evaluation is the cornerstone of primary prevention. Cardiovascular risk estimation systems are widely recommended for use in the primary prevention of cardiovascular diseases. They provide a scientific method for health care professionals to stratify risk, to ensure that those persons at high risk of developing cardiovascular diseases are identified then appropriately managed. In all population, it's essential that individual health care targeting people at raised cardiovascular risk and people with disease is complemented by population-wide public health strategies ${ }^{[11]}$. Although cardiovascular events are less likely to occur in people with low level of risk, no level of risk can be considered "safe". Cardiovascular events will continue to occur in people with low and moderate level of risk and who are the majority in any population ${ }^{[11]}$. The total risk approach for controlling cardiovascular risk factors is more cost effective than a single risk factor approach.

Ultimately, the prevention of CVD depends upon social and economic factors coupled with individual knowledge and motivation. Most individuals are not 'patients' in the traditional setting. They do not exhibit symptoms and signs of their high cholesterol and blood pressure, and hence, the investigator initiated this study, 
In order to motivate the individuals for lifestyle changes at the exhibition making CVD prevention a priority. As per the objective of the World Heart Day-(Theme) 2014- to empower individuals and communities to call for environments that enable them to make positive choices for their heart health. World Heart Day encourages us all to reduce our CVS risk and promote heart healthy earth.

\subsection{Statement of the Problem}

A Descriptive Study to assess the prevalence of cardiac risk factors among people attending the cardiac exhibition at selected hospital, Salem.

\subsection{Objectives}

* To assess the cardiac risk factors among the people attending the cardiac exhibition.

- To determine the association between cardiac risk factors with their selected demographic variables.

\subsection{Hypothesis}

$\mathbf{H}_{1}$ : There is a significant association between the cardiac risk factors among people with their selected demographic variables at $p \leq 0.05$ level.

\subsection{Conceptual frame work:}

Rosentoch's Health Belief Model was adopted for the study.

\section{Methodology}

Quantitative research approach was adopted for the study. The research design chosen for the study was Descriptive research design. Population of the study comprises of people attending cardiac exhibition at selected hospital, Salem. The study was conducted at Sri Gokulam Multi-speciality, 350 bedded Hospital, Salem which is situated at the heart of the city. Sample of this study comprised of people attending cardiac exhibition at Sri Gokulam hospital, Salem. Sample size of study was 169 people who attended cardiac exhibition at Sri Gokulam hospital, Salem. Non probability convenience sampling technique was adopted for selecting the samples.

Criteria for sample selection: People whoever attended the cardiac exhibition above the age of 20 years., both males and females.

Description of tool: Section-A: Demographic data: This section consists of age, gender, educational status, nature of work and family monthly income. Section-B: It consists of health related variables. It includes family history of cardiovascular disease, presence of chronic illness, duration of illness, dietary pattern, habit of exercises, habit of alcoholism, habit of smoking, presence of stress, blood pressure, waist hip ratio, body mass index and age $>40$ years.

\section{Scoring key:}

\begin{tabular}{|l|l|}
\hline Score & Category \\
\hline $0-4$ & Mild risk \\
\hline $5-8$ & Moderate risk \\
\hline $9-12$ & Severe risk \\
\hline
\end{tabular}

\section{Data Collection Procedure}

Data collection was done after obtaining a written permission from the managing director of Sri Gokulam Hospital and verbal consent from the people. The investigator conducted a cardiac exhibition in which a public display of definition, etiology, Patho- physiology, clinical manifestations, diagnostic evaluation prevention and treatment of cardiovascular disease through charts, models, posters and LCD PowerPoint presentations. . After collecting the data from the participants their blood pressure, body mass index and waist hip ratio were checked.

\section{Section-A}

\section{Data Analysis}

Distribution of samples attending cardiac exhibition according to their selected demographic variables.

Table -1: Frequency and percentage distribution of subjects according to their demographic variables

\begin{tabular}{|c|c|c|c|}
\hline & & & \\
\hline S No. & Demographic Variable & Frequency & Percentage \\
\hline 1. & \begin{tabular}{lr}
\multicolumn{2}{l}{ Age In Years } \\
a. & $21-30$ \\
b. & $31-40$ \\
c. & $41-50$
\end{tabular} & $\begin{array}{l}22 \\
49 \\
52\end{array}$ & $\begin{array}{l}13.0 \\
29.0 \\
30.8\end{array}$ \\
\hline
\end{tabular}


Prevalence of Cardiac Risk Factors among People Attending an Exhibition

\begin{tabular}{|c|c|c|c|}
\hline & $\begin{array}{ll}\text { d. } & 51-60 \\
\text { e. } & 61-70 \\
\text { f. } & >70\end{array}$ & $\begin{array}{l}30 \\
9 \\
7\end{array}$ & $\begin{array}{l}17.8 \\
5.3 \\
4.1\end{array}$ \\
\hline 2 & $\begin{array}{ll}\text { Sex } & \\
\text { a. } & \text { Male } \\
\text { b. } & \text { Female } \\
\end{array}$ & $\begin{array}{l}92 \\
77\end{array}$ & $\begin{array}{l}54.4 \\
45.6\end{array}$ \\
\hline 3. & \begin{tabular}{ll}
\multicolumn{2}{l}{ Educational status } \\
a. & Primary \\
b. & Secondary school \\
c. & Graduate \\
d. & Post-graduate \\
e. & No formal education \\
\end{tabular} & $\begin{array}{l}24 \\
74 \\
47 \\
5 \\
19\end{array}$ & $\begin{array}{l}14.2 \\
43.8 \\
27.8 \\
3.0 \\
11.2\end{array}$ \\
\hline 4. & $\begin{array}{ll}\text { Nature of job } \\
\text { a. } & \text { Sedentary } \\
\text { b. } & \text { Moderate } \\
\text { c. } & \text { Heavy } \\
\end{array}$ & $\begin{array}{l}7 \\
156 \\
6 \\
\end{array}$ & $\begin{array}{l}4.1 \\
92.3 \\
3.6 \\
\end{array}$ \\
\hline 5. & \begin{tabular}{ll}
\multicolumn{2}{l}{ Family monthly income(in Indian rupees) } \\
a. & Below 5000 \\
b. & $5,001-10,000$ \\
c. & $10,001-15,000$ \\
d. & Above 15,000
\end{tabular} & $\begin{array}{l}24 \\
39 \\
37 \\
69\end{array}$ & $\begin{array}{l}14.2 \\
23.1 \\
21.9 \\
40.8\end{array}$ \\
\hline
\end{tabular}

The table above shows regarding the age of the clients $52(30.8 \%)$ belong to $41-50$ years of age, $49(29 \%)$ belong to $31-40$ years of age and only $7(4.1 \%)$ belong to the age group of more than 70 years. Regarding gender 92(54.4\%) were males and the rest were females. Regarding the educational status, 74(43.8\%) have completed the secondary school, $47(27.8 \%)$ were graduates and only $19(11.2 \%)$ did not have any formal education. Regarding the nature of job majority $156(92.3 \%)$ were moderate workers. Regarding family monthly income majority 69(40.8\%) have monthly family income of more than 15000 Indian rupees.

\section{Section-B}

Distribution of samples attending cardiac exhibition according to their selected health related variables.

Table-2: Frequency and percentage distribution of subjects according to their health related variables.

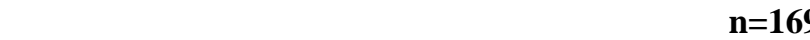

\begin{tabular}{|c|c|c|c|}
\hline \\
\hline S No. & Demographic Variable & Frequency & Percentage \\
\hline 1. & \begin{tabular}{l}
\multicolumn{2}{l}{ Age in years } \\
a. $\quad$ Less than 40 \\
b. $\quad$ More than 40
\end{tabular} & $\begin{array}{l}71 \\
98\end{array}$ & $\begin{array}{l}42.0 \\
58.0\end{array}$ \\
\hline 2 & $\begin{array}{l}\text { Family history of heart diseases } \\
\begin{array}{l}\text { a. } \\
\text { b. }\end{array} \quad \text { Yes } \\
\text { No }\end{array}$ & $\begin{array}{l}14 \\
155\end{array}$ & $\begin{array}{l}8.28 \\
91.72\end{array}$ \\
\hline 3. & $\begin{array}{l}\text { Presence of DM \& hypertension } \\
\begin{array}{ll}\text { a. } & \text { Both diseases } \\
\text { b. } & \text { Single } \\
\text { c. } & \text { None }\end{array}\end{array}$ & $\begin{array}{l}9 \\
45 \\
115\end{array}$ & $\begin{array}{l}5.33 \\
26.68 \\
68.04\end{array}$ \\
\hline 4. & $\begin{array}{l}\text { Duration of illness (if yes) } \\
\text { a. } \quad<2 \text { years } \\
\text { b. } \quad>2 \text { years }\end{array}$ & $\begin{array}{l}14 \\
40\end{array}$ & $\begin{array}{l}25.92 \\
74.06\end{array}$ \\
\hline 5. & $\begin{array}{ll}\text { BMI } & \\
\text { a. } & \text { Normal } \\
\text { b. } & \text { Overweight } \\
\text { c. } & \text { Obesity }(\text { Grade }- \text { I) } \\
\text { d. } & \text { Obesity (Grade }- \text { II) } \\
\text { e. } & \text { Obesity (Grade }- \text { III) } \\
\text { f. } & \text { Underweight }\end{array}$ & $\begin{array}{l}70 \\
61 \\
19 \\
7 \\
7 \\
5\end{array}$ & $\begin{array}{l}41.4 \\
36.09 \\
11.24 \\
4.14 \\
4.14 \\
2.9\end{array}$ \\
\hline 6. & $\begin{array}{ll}\text { Blood pressure (JNC 7 classification ) } \\
\text { a. } & \text { Optimal } \\
\text { b. } & \text { Pre-hypertension } \\
\text { c. } & \text { Stage - I } \\
\text { d. } & \text { Stage - II } \\
\end{array}$ & $\begin{array}{l}58 \\
79 \\
30 \\
2\end{array}$ & $\begin{array}{l}34.3 \\
46.7 \\
17.75 \\
1.18\end{array}$ \\
\hline 7. & $\begin{array}{l}\text { Habit of exercise } \\
\begin{array}{l}\text { H. } \\
\text { a. }\end{array} \text { Yes } \\
\text { b. } \quad \text { No }\end{array}$ & $\begin{array}{l}94 \\
75\end{array}$ & $\begin{array}{l}55.6 \\
44.4 \\
\end{array}$ \\
\hline 8. & 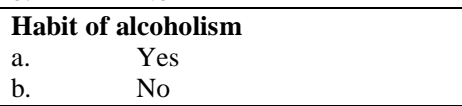 & $\begin{array}{l}29 \\
140\end{array}$ & $\begin{array}{l}17.2 \\
82.84\end{array}$ \\
\hline 9. & 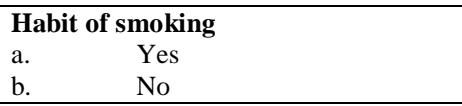 & $\begin{array}{l}15 \\
154 \\
\end{array}$ & $\begin{array}{l}8.87 \\
91.12\end{array}$ \\
\hline 10. & Presence of stress & & \\
\hline
\end{tabular}


Prevalence of Cardiac Risk Factors among People Attending an Exhibition

\begin{tabular}{|l|l|l|l|l|}
\hline & a. & Yes & 45 & 26.6 \\
& b. No & 124 & 73.4 \\
\hline $\mathbf{1 1 .}$ & Dietary status & & \\
& a. $\quad$ Vegetarian & 24 & 14.2 \\
& b. Non-vegetarian & 145 & 85.8 \\
\hline $\mathbf{1 2 .}$ & Family history of HT/ DM & 74 & \\
& a. Yes & 95 & 43.70 \\
& b. No & & 56.21 \\
\hline
\end{tabular}

\section{Section B}

The distribution of people who attended cardiac exhibition according to their selected health related variables. According to age 71(42\%) were above the age of 40 years. According to the family history of cardiovascular diseases, majority of the people $155(91.72 \%)$ were not having family history of cardiovascular diseases. Most of the people 115(68.04\%) were not having any history of chronic illness. For those who had chronic illness, $40(74.06 \%)$ of the people were having duration of illness for more than 2 years. Majority of the people $145(85.81 \%)$ were non-vegetarians. $75(44.4 \%)$ were not having the habit of doing exercises and majority of the people 140(82.89\%) were non -alcoholic .According to their habit of smoking majority of the people 154(91.12\%) were non-smokers. According to their stages of hypertension it revealed that $99(46.70 \%)$ of the people belong to pre hypertension stage as per JNC 7 criteria $30(17.75 \%)$ were in stage I hypertension $2(1.18 \%)$ were in stage II hypertension and 58(34.3\%) had optimal BP. As per BMI, 19(11.24\%) were overweight and obese 61(36.09\%) were obesity Grade -II. 95(56.21\%) had no family history of hypertension and diabetes mellitus, $74(43.70 \%)$ had family history of hypertension and diabetes mellitus

\section{Section C}

Distribution of level of risk among people who attended cardiac exhibition according to their health related variables.

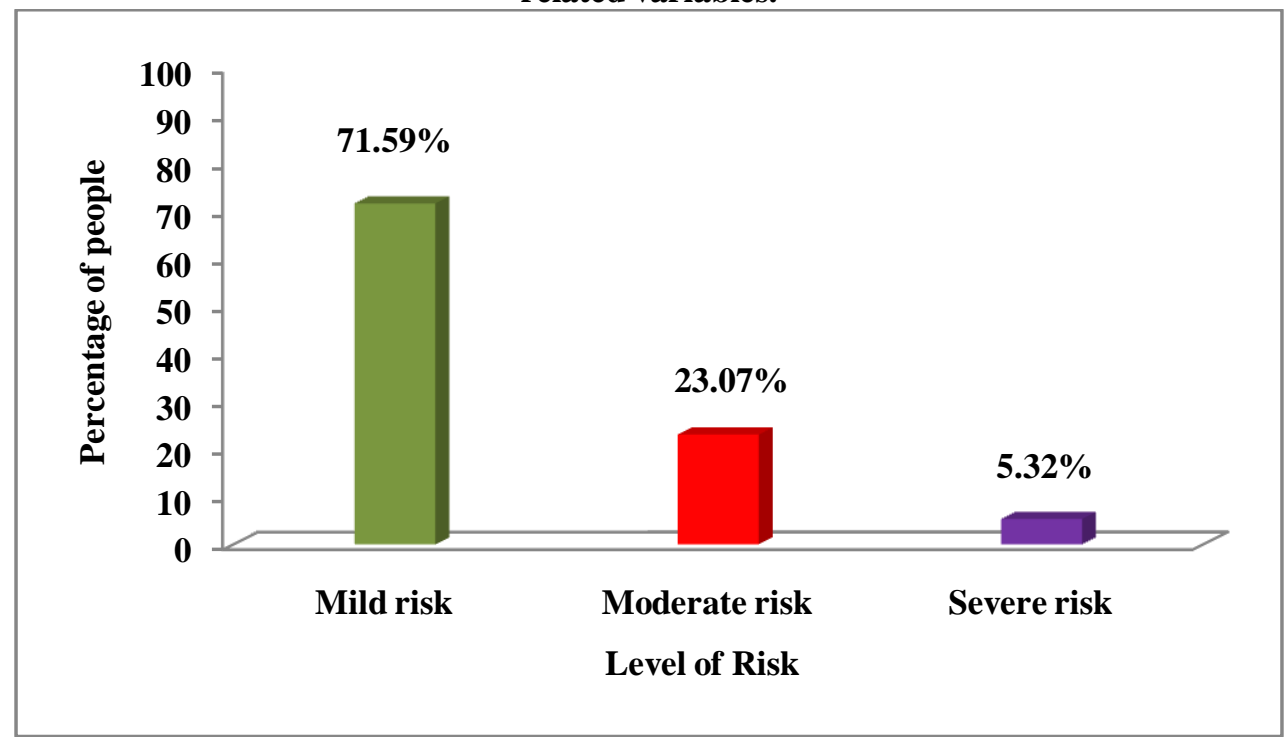

Fig:-1 Percentage distribution of samples according to the level of risk among people who attended cardiac exhibition according to their health related variables.

The above bar diagram shows that 121(71.59\%) people had mild risk, 39(23.07\%) people had moderate risk and $9(5.32 \%)$ people had severe risk for developing cardiac diseases.

\section{Section D}

Table-3: Association of risk factors among people who attended the cardiac exhibition with their selected demographic variables .

\begin{tabular}{|l|l|l|l|l|}
\hline S No. & Demographic Variable & df & $\chi^{2}$ & Table value \\
\hline 1. & Age & 10 & $20.17^{*}$ & 18.31 \\
\hline 2. & Gender & 2 & 4.4832 & 5.99 \\
\hline 3. & Educational status & 8 & $45.63^{*}$ & 15.51 \\
\hline 4. & Nature of job & 4 & $15.02^{*}$ & 9.49 \\
\hline 5. & Monthly income & 6 & $20.703^{*}$ & 12.59 \\
\hline 6. & Family history of heart diseases & 2 & $30.2371^{*}$ & 5.99 \\
\hline 7. & Presence of chronic illness & 6 & 11.898 & 12.59 \\
\hline 8. & Blood pressure & 6 & $14.288^{*}$ & 12.59 \\
\hline 9 & BMI & 10 & $26.8848^{*}$ & 18.31 \\
\hline
\end{tabular}


There was a significant association of risk factors among patients who attended cardiac exhibition with their selected demographic variables such as age, educational status, nature of job, monthly income, blood pressure and BMI. Hence the research hypothesis $\left(\mathrm{H}_{1}\right)$ is retained for the same at $\mathrm{p}<0.05$ level and it is rejected for other variables.

\section{Discussion}

The present study finding is supported by Rajah Rasiah et.al., in Malaysia (2013) who conducted a study on 11,959 adults aged 30 yrs and above living in urban and rural areas to examine the prevalence of CVD risk factors, the association between these factors and the demographic variables .The results showed an association between CVD risk factors and education and income was mixed . There was a negative association between smoking and hypertension and education and income .Regarding the association between diabetes , hypertension ,high blood cholesterol levels and being overweight, urban men showed higher prevalence of being overweight than rural men ${ }^{[12]}$.

\section{Conclusion}

This study concludes that the cardiac risk factors among the 169 Peoples who attended the cardiac exhibition at a selected hospital, Salem, 121(71.59\%) people were at mild risk, 39(23.07\%) people were at moderate risk and $9(5.32 \%)$ people were at severe risk of developing cardiac diseases.

\section{Recommendations}

- The same study can be conducted at various settings.

- A similar study can be conducted with a specific population.

- An experimental study can be conducted emphasizing the importance of Teaching about the risk factors especially to younger population as CAD Risk factors start at a younger age.

- Same study can be conducted for a larger population.

- Same study can be conducted emphasizing the use of lipid profile tests for the subjects.

\section{Acknowledgement}

I thank all the higher officials, and the clients that have extended their cooperation in completing this study.

\section{References}

[1]. Murrey C J. et.al., (1997). Mortality by cause for eight regions of the world. Global burden of disease study. Lancet. 349:12691276

[2]. WHO. Diet, nutrition and the prevention of chronic diseases .WHO Technical Report Series .916.WHO, Geneva 2003.

[3]. WHO Global atlas on cardiovascular diseases prevention and control, Geneva 2011.

[4]. Heart disease and stroke statistics 2006 update. A report from the American Heart Association statistics committee and stroke statistics subcommittee. Circulation. 2006;113:e85-e15

[5]. WHO. The global burden of disease: 2004 update. Geneva, WHO .2010.

[6]. Vinith Kumar A.et.al. (2012).Prevalence and prognosis of RV infarction in inferior wall .Asian Journal of Clinical Cardiology.vol.14 No: 12.April 2012.page 409-448.

[7]. Wilson P W.et.al.Prediction of coronary heart disease during risk factor categories .circulation 1998 .9711837-1847

[8]. NCEP Expert panel on detection, evaluation and treatment of high blood cholesterol in adults final report .circulation 2002.106 :3143-3421

[9]. Tunstall P.The Dundee Risk Disc for management of change in risk factors .European Heart Journal 1991.303; $744-747$.

[10]. Assmann G.et.al. The prospective Cardiovascular Munster (PROCAM) study: prevalence of hyperlipidemia in persons with hypertension and /or diabetes mellitus and the relationship to coronary heart disease .Am Heart Journal 1988. 116:1713-1724.

[11]. Conroy R M.et.al .Estimation of ten year risk of fatal cardiovascular disease in Europe: the SCORE project. European Heart Journal 2003.24:987-1003

[12]. Rajah Rasiah et.al.(2013).CVD risk factors and socioeconomic risk factors and socioeconomic variables in a nation undergoing epidemiologic transition(Malaysia).BMC public health 2013,$13 ; 886 ; 1471-2458$. 